\title{
Freirean critical consciousness in a refugee context: a case study of Syrian refugees in Jordan
}

\author{
Arran Magee and Tejendra Pherali \\ UCL Institute of Education, 20 Bedford Way, London WC1H OAL, UK
}

\begin{abstract}
This paper argues that education underpinned by critical pedagogies offers an alternative for engaging with the complexities of conflict, peace and social transformation in refugee contexts. Drawing upon a semi-ethnographic qualitative study with a focus on a non-formal educational programme for supporting Jordanian and Syrian refugee youth, we find that participatory pedagogies provide a promising mechanism for reaching out-of-school refugees in host communities. However, a series of intersecting factors, namely the perception that empowerment education is antithetical to the goal of gaining certification, leads to manipulation of the pedagogies. Hence, empowerment education risks being co- opted by the 'banking model' of education. The paper critiques the dominant market-oriented education and suggests an alternative approach to engage with challenges in refugee contexts.
\end{abstract}

KEYWORDS: Refugee education; Jordan; Syrian crisis; critical pedagogies; social transformation

\section{Introduction}

Globally, 65.3 million people are forcibly displaced, including 21.3 million refugees, over half of whom are under the age of 18 (UNHCR 2016d). Afghan, Somali and Syrian refugees account for over $54 \%$ of the total global refugee population, and the Syrian conflict is the single largest source, accounting for 4.9 million Syrians taking refuge in neighbouring countries, including, Jordan, Lebanon and Turkey, as well as in Europe and North Africa. In 2015, Jordan was home to an estimated 230,000 school-aged Syrian refugee children, which poses an enormous challenge for the provision of education (UNHCR 2016c).

It has been recognised that education can play a significant role in supporting refugee children's psychological and social wellbeing by aiding their integration into local communities, contributing generally to the social, economic and political stability of refugee communities and providing the human and social capital needed for post-war development (Crisp, Talbot, and Cipollone 2001; Price 2011). Yet, despite continued investment and the opening of formal schools to Syrian refugees, 35\% of refugee children in Jordan are reported to be out of school and youth aged 12-17 are found to be the most likely group to have never attended any formal schooling after their arrival in Jordan (JENA 2015; UNHCR 2016b). 
Moreover, almost a third of those enrolled drop out within a six-month period (JENA 2015). International agencies have come to recognise that routine responses cannot meet the educational needs of children in emergencies and that a need exists for new approaches that can deliver quality educational services in crisis settings (UNHCR 2016a).

As the formal state provision struggles to cope with the influx of refugee children, nonformal and informal education programmes have gained increasing international attention as viable alternatives. In the latest international funding appeal for the Syria response in Jordan, nearly US $\$ 40$ million was requested for 2016 to enrol 80,000 children in informal education and 6,000 children in non-formal education programmes (Dhingra 2016). An additional \$64.6 million has been requested for 2017 and 2018, suggesting that international organisations have no intention of scaling down these programmes in the near future (Dhingra 2016). However, these responses have often focused on filling gaps in existing education mechanisms, without accounting for the political and economic sanctions as well as the systemic exclusions that prevent refugees from employing the new skills they acquire through education (Betts and Collier 2015; ILO 2015). These restrictions can, in turn, lead to frustration and a risk of violence and extremism (Davies 2009; Urdal 2006).

A promising, yet under-researched alternative is grounded in the teachings of Paulo Freire (2000), who proposes that progressive pedagogies produce teachers and learners who, through the process of listening, dialogue and critical reflection, can awaken critical consciousness about social realities. In turn, individuals are believed to engage in socially transformative actions to challenge oppressive structures based on their new understandings, resulting in the redistribution of resources and decision-making in ways favourable to oppressed communities (Freire 2000). As Davies (2009) notes, these shifts have the potential to reduce violence and extremism at home and abroad.

This paper investigates a non-formal education programme underpinned by the Freirean notion of critical consciousness to analyse the efficacy of Freirean pedagogies for Syrian refugee youth in Jordan. It presents the findings of a semi-ethnographic qualitative study (Alvesson and Sköldberg 2009) of Syrian refugee youth enrolled in Questscope programmes in Jordan that, in partnership with the Jordanian Ministry of Education, provide education to some 3500 youth of various nationalities (Questscope 2016). The findings provide important insights into the role of Freirean pedagogies in refugee contexts for current and future programming. The first section introduces Freire's theory of critical consciousness. The second section provides a critical analysis of the current education situation faced by Syrian refugee youth in Jordan, which is followed by a brief summary of the research methods employed to gain empirical data. The final section presents the key findings of the research and critically discusses the relevance of Freirean pedagogies in refugee contexts.

\section{Freirean critical consciousness and education in refugee contexts}

For Freire, education is always seen as 'an action either for the domestication of people or for their liberation' (Freire 1985, 99). Whilst mainstream education approaches are often seen as adopting what Freire terms 'banking education', in which knowledge is deposited into passive recipients by a ruling elite without critical questioning, Freirean pedagogies promote the liberation of learners from their unquestioning acceptance of life and their believed inability to effect social change. The educator's role is to move beyond traditional banking education and instead engage in critical dialogue to teach how to read and write 
in relation to the awakening of consciousness about social realities (Freire 2000, 2013). Freire terms this consciousness 'conscientization' and believes that with it, individuals can recognise their potential for action and act according to their new understanding. The goal of conscientisation, therefore, is not just to deepen understanding, but to invoke praxis; that is, informed action understood to have the power to challenge oppressive structures (Freire 2000, 2013; Taylor 1993). Sanders (1968, as cited in Nyirenda 1996, 4) provides a helpful definition of conscientisation as:

An 'awakening of consciousness', a change of mentality involving an accurate, realistic aware-ness of one's locus in nature and society; the capacity to analyse critically its causes and consequences, comparing it with other situations and possibilities; and action of a logical sort aimed at transformation. (Sanders, 1968, cited in Nyirenda 1996, 4)

Previous studies have suggested that programmes underpinned by the Freirean notion of critical consciousness can provide refugees and internally displaced populations with a wealth of benefits (McCaffery 2007). Community-based participatory and transformative literacy projects for refugees and Internally Displaced People (IDPs) in Sierra Leone and Sudan were found to have made a significant contribution to personal healing, com-munity reconstruction and cohesion, adult literacy and peacebuilding and reconstruction (McCaffery 2007). Similarly, El-Salvadorian refugees in UN-supported refugee camps in Honduras found Freirean education to be a flexible and low-cost learning opportunity that significantly increased literacy and self-empowerment (Hammond 1998). Moreover, recent evidence in the field of education has shown that an internal locus of control appears to be important in shaping a broad range of outcomes such as educational attainment, labour market success, socioeconomic status, mental health and wellbeing and some health measures and health behaviours (Goodman et al. 2015).

However, the amount of evidence testifying to the efficacy of Freirean pedagogies remains severely limited (Mohajer and Earnest 2009), and a lack of knowledge exists with respect to the potential for critical pedagogies to enable transformative learning among refugee learners. Therefore, this study, seeks to reveal the ability of an education programme under-pinned by the Freirean notion of critical consciousness to invoke transformative action, focusing on the case of Syrian refugees in Jordan.

A significant challenge in doing so involves measuring transformation. Transformative education relies largely on educational outcomes, deemed antithetical to measurement (Kabeer 1999). It is therefore helpful to make a distinction between empowerment as a process and as an outcome. Empowering processes are those through which people create or are given opportunities to control their own destinies and influence the decisions that affect their lives, whereas empowerment outcomes refers to the consequences of those processes (Zimmerman 1995). Whilst the latter may remain antithetical to measurement, the former allows for the identification of key environmental features conducive to empowerment. Although the existence of these features cannot guarantee empowerment, they provide a useful entry point for analysis.

We draw upon a critical social theory and the youth empowerment model, which Jennings et al. (2006) present as 'dimensions of Critical Youth Empowerment' (CYE):

(1) A welcoming and safe environment;

(2) Meaningful participation and engagement;

(3) Equitable power sharing between youths and adults; 
(4) Engagement in critical reflection on interpersonal and sociopolitical processes;

(5) Participation in sociopolitical processes to effect change;

(6) Integrated individual- and community-level empowerment.

These dimensions encompass the "processes and contexts through which youth engage in actions that create change in organisational, institutional, and societal policies, structures, values, norms, and images' (Jennings et al. 2006, 40); or in the Freirean lexicon: facilitate praxis. We utilise these tools to analyse the efficacy of an education programme for Syrian refugee youth in Jordan underpinned by the Freirean (2000) notion of critical consciousness.

\section{Education in crisis - Syrian refugee youth in Jordan}

Having claimed more than 470,000 lives and forcibly displacing more than 4.8 million Syrians to neighbouring countries, the Syrian conflict has caused an enormous amount of human suffering (SCPR 2015; UNHCR 2016c). Residing in Jordan are more than 650,000 refugees, of whom 230,000 are school-aged children (UNHCR 2016c). The poor economic conditions refugees face jeopardise their ability to cover the costs of school materials and force them into the informal employment market, which has contributed to the fact that an estimated $17 \%$ of secondary-age refugee youth have never attended school and that one-third of those enrolled are likely to drop out before completion (Ahmadzadeh et al. 2014; JENA 2015). Moreover, Syrian refugees who have missed more than three years of schooling are unable to re-enrol and are likely to lose their chance to return to school (JENA 2015).

A parallel provision of non-formal education (NFE) has been a transitional solution to cope with the demands and diverse learning needs of refugee youth. Whilst students value nonformal education as high quality, learner-friendly, cost-effective and applicable to their professional aspirations, a common concern amongst refugee communities is the lack of certification (Ahmadzadeh et al. 2014; JENA 2015). Non-formal education often operates in isolation from formal education systems and certification processes elsewhere, limiting opportunities for future employment, community assimilation and transition back home (Kirk 2009). A government-endorsed grade 11 school certificate is also a requirement for sitting for official grade 12 examinations in Jordan; thus, youth enrolled in uncertified non-formal education programmes will find their future educational opportunities restricted (Ahmadzadeh et al. 2014; INEE 2010; Mercy Corps 2014).

An exception, however, has been the education programming provided by Questscope, a Jordanian non-governmental organisation that was originally established to serve disadvantaged Jordanian youth who had dropped out of school and who face challenges in adopting a stable social life. Today, Questscope, in partnership with the Jordanian Ministry of Education, provides certified 10th grade Jordanian education to Jordanian youth and Syrian refugee youth in mixed-nationality classrooms for students aged 13-18 for boys and 13-20 for girls. They specifically support students from disadvantaged backgrounds, those who have had a break in their education or those who have been out of education too long to re-enrol in formal programmes. Through a holistic, nondiscriminatory approach in selecting students and the provision of educational programmes, Questscope mitigates the conditions of unequal political rights between Jordanian youth and Syrian refugees from a programmatic point of view. 
The education programme consists of an abridged curriculum focusing on English, Arabic, Maths and Science, which has been developed in collaboration with the Jordanian Ministry of Education. All teaching and extra-curricular activities at the centre are under-pinned by the pedagogies of Paulo Freire (2000), which enable Questscope facilitators to pro-mote democratic decision-making processes in which the facilitator is an equal participant in the dialogue and plays an important role to actively engage students not only in learning processes but also in programme design, such as determining programme guidelines and deciding learning topics. It also entails critically reflecting on topics through analysis of a "nus almuwalad' (seed text), that is, a sentence formulated through group discussions of and debates about the chosen topic. The nus al-muwalad acts in ways similar to Freire's (2013) 'generative words' in that it provides a focus for dialogue and critical reflection.

Classes take place for two hours a day, five days a week in Jordanian government schools according to the Jordanian normal school hours, and are taught by Jordanian teachers appointed by the Ministry of Education. Boys and girls are taught in separate schools to address the parental concern about potential harassment in co-education settings. To make up for lost teaching hours, classes run all year instead of observing the summer holidays of the Jordanian school system. Within each school, the classes are broken down into three cycles, each cycle lasting eight months and covering the equivalent of four grades of Jordanian schooling from grades one through ten. The teaching staff consists of full-time teachers from the Jordanian school system who volunteer extra hours of paid work. The training of teachers, who are referred to as facilitators in the programme, is covered in 100 hours of discussion and interaction in organised settings, $80 \%$ of which takes place during one's first year as an NFE facilitator, in addition to hours of observation and accompaniment invested by educational coordinators, educational specialists and quality assurance teams. Once they have begun the training, staff are referred to as facilitators rather than teachers. Staff teaching English and Information Technology, however, do not go through the same training process.

While providing certified education, the main objective of the programme is to create a safe and nurturing learning environment while promoting social and emotional wellbeing. Youth in Jordan, especially Syrian refugee youth, experience psychosocial challenges that can significantly affect learning. Advances in the understanding of brain development have suggested that children and youth are susceptible to long-term negative effects on their learning when they encounter extreme and sustained stress, such as that experienced in conflict or extremely disadvantaged settings (INEE 2016). When such stress is not mitigated through alternative experiences that deactivate or reduce the brain's physiological responses, it can become toxic and affect brain development and functioning in both the short and long term (Blair, Granger, and Peters Razza 2005; AAP 2012). This has proven effects on both cognitive and non-cognitive development and on learning outcomes (Irigaray et al. 2013).

At the same time, these advances show that children can be incredibly resilient in the face of such adversities when they are provided with safe and nurturing relationships and development opportunities (INEE 2016). Thus, NFE for these children and youth requires well designed interventions that address the effects of such adversity in their lives so that they can learn and thrive.

Questscope has developed a participatory learning methodology to enhance students' social and emotional skills (Oxford Stakeholders Study 2011) and that is integrated into all cycles of the NFE programme, from the initial cycle to the final certification. 
This research focuses primarily on the efficacy of NFE underpinned by the Freirean notion of critical consciousness to evoke praxis, as defined by Freire (1985) and outlined by Jennings et al.’s (2006) framework of Critical Youth Empowerment.

\section{Methodology}

This paper draws on a semi-ethnographic reflexive study (Alvesson and Sköldberg 2009) designed to explore the perceptions and experiences of refugee youth and staff who participate in non-formal education for youth empowerment. The study utilised individual and focusgroup interviews and observations of seven Questscope non-formal education centres over a two-month period between June and August 2015 and in six districts in Jordan: Aljoun, Al Marfraq, Amman, Al Karak, Irbid and Maan. The researchers engaged with participants' narratives, trying to capture the meaning of their educational and social lives ethnographically as well as examining broader stakeholders' views about educational processes. The individual and focus-group interviews were conducted immediately after lessons in the same school where the classes were conducted. Focus-group interviews, each of which lasted no longer than 45 minutes, were attended by both Syrian and Jordanian students. All the formal interviews were recorded in Arabic and transcribed into English with the help of an interpreter and written notes were taken in English throughout the fieldwork. In one of the centres in Amman, a larger group activity was used in which the students sat together and created mind maps, answering the questions posed by the researcher. Observations drew on Rodgers (2004) 'Hanging out with forced migrants' approach, which advocates for 'intensive informal and interpersonal interactions between researchers and the forced migrants' to gain perspectives about the multi-dimensional and complex nature of forced migration whilst sustaining humanism to research that is 'essential for informing ethical and accountable policy decisions' (Rodgers 2004, 48-49). All the gathered data was later coded for thematic analysis.

In most centres, Jordanian and Syrian youth were interviewed together. Official enrolment figures across the selected centres were reported to be 141 male and 28 female Syrian students, and 71 male and 8 female Jordanian students. The research, however, took place over multiple visits and the number of students attending on any particular day varied. On occasion, when class sizes were large, a small proportion of the students was selected conveniently for focusgroup discussions. Eleven students were also interviewed individually. Similarly, 11 Questscope staff members, 5 Jordanian teachers and 6 Ministry of Education (MoE) Liaison officers participated in in-depth interviews. Interviews with Questscope staff were conducted in English, whilst interviews with students and three of the MoE Liaisons were undertaken in Arabic with the assistance of one of three volunteer translators who provided support throughout the research process.

At the time of the research, Questscope was in the midst of rolling out 60 new centres, whilst handing over its pre-existing 28 centres to the Jordanian Ministry of Education. These changes meant most of the facilitators and learners who participated in our study were in their first year of the Questscope programme and were receiving their first year of exposure to critical pedagogies, hiding some of the changes that may occur over time. 


\section{Findings}

\section{A welcoming and safe environment}

The facilitators and teachers at Questscope made efforts to create a welcoming and safe environment in which youth felt valued, respected for who they were, encouraged and supported for positive social development. A significant benefit of this environment in the refugee context was the gradual integration of Syrian refugees into classrooms of mixed nationalities. A student from Maan notes:

We used to hate each other [Jordanians and Syrians], even when we first started. Now, we have had the chance to get to know each other, and talk about things, now we celebrate each other's birthdays together.

A teacher in Amman explains how the environment also facilitated enrolment and reduced dropouts:

It is because here we are equals. We are all friends here, we are like one big family. Students come back to class because they want to be here, I am their friend. We feel we belong to each other.

An Education Coordinator suggests that these gains are the result of the high-quality teachers found through the recruitment process and their ability to create strong bonds with students of all nationalities. Most importantly, it portrays a different pedagogical philosophy - one concerned with non-hierarchical values such as equality, mutual respect and active participation among learners (Andersson, Hinge, and Messina 2011). One of the staff members mentioned:

Of course, we have good teachers [and facilitators] here, that is the only way we can get students to stay. They [the teachers and facilitators] don't have to do this job, it is a little extra money which is good, but if you really hated your job - which I think some teachers in Jordanian schools do - then those people are not going to come and work [at Questscope]. (Education coordinator)

Whilst schools for Syrian refugees in Jordan are often reported as sites of violence and discrimination (JENA 2015), Questscope appeared to have created a welcoming and safe environment for pupils of both Jordanian and Syrian nationalities. Jennings et al. (2006) suggest these environments in which 'youth have a sense of ownership and yet are challenged and supported to move beyond their usual comfort zone' (41) can enable them to share their feelings, voice their opinions in decision-making processes, take risks and begin to feel a sense of belonging in the community. In this instance, the environment also resulted in improved student retention. In a refugee context, in which retention and integration remain a significant challenge and an objective for many organisations (UNHCR 2011), the Questscope approach can provide a promising model.

\section{Meaningful participation and engagement}

Learners felt that their participation and engagement in learning activities was meaningful to their lives and involved an opportunity to shape their own lessons. There were no set timetables for covering topics, and an overlap was encouraged. Students expressed great satisfaction with the provision that they could influence the terms of the programme. A Questscope Emergency Youth Responder provides an example of a facilitator engaging students in meaningful participation and engagement: 
When you see facilitators working well, it is a beautiful thing. I remember seeing a group of kids in the playground, standing in a circle. The facilitator walked over and joined the circle, and just began chatting to them. One of the kids suddenly started talking about something they had seen on TV about sharks; you know, how kids just suddenly start talking about random things. The facilitator started asking questions about sharks and jumped straight into the lesson he had to teach that week on animal science, right there in the playground.

Participation can allow youth to learn and practise leadership whilst undertaking different roles and responsibilities which, as Cargo et al. (2003) argue, can lead to the sustained and prolonged engagement necessary for skill development, mastery and positive youth identity development. Through this process, young people also begin to recognise each other's strengths and to value partnerships and collaboration, helping to bridge divides and integrate them into larger social worlds (Chinman and Linney 1998; Jennings et al. 2006; Kim et al. 1998). The sense of belonging that can come with participation has also been associated with lower levels of depression and higher self-efficacy, regardless of the level of past exposure to adversities, helping to yield most of the psychosocial benefits of education (Kia-Keating and Ellis 2007).

However, concerns were raised about a perceived incompatibility between meaningful participation in learning and the need for formal accreditation. A large majority of the facilitators perceived the Questscope teaching methods to be antithetical to passing final exams and gaining a certificate. When combined with the demand for certification in refugee contexts, many facilitators opted to overlook participation and engagement and promoted rote learning methods to allow for greater success in final examinations. A facilitator in Karak explains:

I believe it is very important to keep the students interested and involved, and to use these teaching methods, they work, they do. Sometimes I use them in my other lessons now. But I don't think I can teach everything to pass the tests with such little time and so much to do if we treat the classes like this. (Karak)

Similarly, an English teacher in Amman notes:

It is too difficult to teach the levels of English they need if I can't repeat activities, and keep them focused on one task. It is important they participate, but sometimes that means we lose so much time. I can teach less, but I want these students to do well.

On occasion, facilitators suggested it was student participation and engagement itself that caused the shift towards less participation. A facilitator in Irbid explains:

What is most important is that they [students] shape their own education, so what can I do?

They want a certificate, I will teach for a certificate. I can't do both.

It appeared therefore, that many facilitators and students perceived participation and examination to be antithetical. The perception led to a gradual shift from participatory and holistic learning to constrained approaches aimed at achieving prescribed goals meriting formal recognition. In one instance, students were seen using their participation to manipulate participatory pedagogies into a microcosm of its conventional, rote counterpart - or what Freire (2000) refers to as 'banking' education - deemed most suitable for gaining human-capital-based preparation for employment.

A senior Questscope staff member suggests that these views can be common amongst facilitators; however, they can be overcome as facilitators gain a greater understanding of the methodology: 
The first four months is teaching the facilitator that you need to reinforce, things other than certification. The best facilitators read the book the night before. They walk into the class. And the first thing that happens is what you use to teach the class that day. So, we know we have to get kids to the final test. But that is not the primary goal. The facilitators, for at least the first four months, the art of the thing is to make them feel ok that it's not a primary goal, the testing.

This explanation helps to some extent to explain the different approaches of the teachers observed, with some teaching without textbooks and with participation from the class, whilst others resorted to rote learning methods. It doesn't, however, overcome the paradox created between participation and the demands of the students, who largely insisted on rote learning in line with their educational expectations. This suggests the shift may, in fact, be the result of a de-prioritisation of certification, rather than a newfound compatibility.

\section{Equitable power sharing between youth and adults}

As other empowerment models have noted (Cargo et al. 2003), equitable and shared power between youth and adults creates a conducive environment for reflective learning, one where all individuals treat each other with mutual respect and dignity. One strategy for promoting CYE is through the gradual transfer of decision-making power from adults to youth. However, the momentum of the shift, as Cargo et al. (2003, S71-S72) note, depends on the practitioners' level of experience and knowledge of the youth. Each Questscope centre that was visited had adopted its own balance of power within the classroom, guided by the facilitator. A facilitator in Irbid explains:

It is absolutely important to share the classroom with everyone, we treat each other with respect, the same. But it does depend on the class. Some of these students are from very vio-lent backgrounds, have been through awful things, and fight back. You know, not physically, just questioning and arguing and everything else. In these classes, I keep much more control.

It appeared therefore, that power sharing existed, though the degree to which it occurred varied among the centres. It was revealed that equitable power sharing may not be achieved or that the practice can even be counter-productive before ground rules about mutual respect and understanding are established and followed by everyone.

One of the key methods of establishing ground rules was the creation of 'class constitutions' in which the facilitator and learners set the rules for behaviour in the classroom. These constitutions are posted for everyone to read, and they outline rules such as speaking in turn and how to handle disagreements between learners. Jennings et al. (2006) suggest that these models help support the development of valuable leadership skills to gradually and effectively transfer power or real opportunities for organisational decision-making. However, the responsibility placed on the facilitator to gradually transfer decision-making alludes to the significance of effective teacher training.

Most notable demonstration of equitable power sharing between youths and adults, however, occurred at the macro level, during the tawjihi examinations (the Jordanian general secondary exams). The schools where Questscope centres operated were temporarily closed to all external staff and students to allow for state-wide examinations. As such, a centre in Karak was forced to bar Questscope students during the tawjihi week. To overcome this issue, an education co-ordinator organised a meeting with students, centre facilitators and liaison officers from the Ministry of Education. All parties gathered at the school to find a mutually agreeable solution. After a 30-minute group discussion, the group reached a 
consensus that lessons would be one hour longer for the following two weeks to compensate for the missed lessons. In a discussion after the meeting, an education coordinator suggested that participatory decision-making had not only provided an empowering mechanism, but had also given students ownership of the agreed-upon solution. They argued that, in doing so, the students are more likely to abide by the decision:

The students made the decision so now they will accept the decision. If I had gone in and told them what to do, they might not come back to school. Now it is theirs. When you choose, you believe. (Education coordinator)

Later, however, in a follow-up interview with the education coordinator, it was revealed that some steering had occurred to achieve the outcome the students had reached:

Education coordinator: Yes, we discussed it at the office, we wanted this outcome too.

Researcher: Why this outcome?

Education coordinator: This was the only option really. The Ministry of Education needs the buildings, and we have no choice.

Researcher: So how much did the students choose this, and how much did you choose it and sell it to them?

Education coordinator: The students chose it, I didn't tell them what they wanted to do.

Researcher: So, this was just the best option?

Education coordinator: Yes. But you know, sometimes when your wife goes to the shop thinking she wants to buy a [loaf of] bread, and you place a banana by the door, they will come home with a banana instead. They still chose the banana. They still chose it. I just helped them choose it.

This conversation reveals nuances in the potential for participatory decision-making. At the micro, classroom level, facilitators were able to transfer power to the students, yet at the macro level, powerful state-centric policies superseded the needs of refugees competing for limited resources. In this instance, a demand from the Ministry of Education intersected with the empowerment programme and forced the coordinator to guide the students towards a prefigurative solution. Jennings et al. (2006) suggests that these forms of token participation rarely result in youth empowerment or real opportunity to influence organisational decision-making. Instead, they merely fulfil the administrative needs of equitable power sharing.

In this situation, however, the circumstances also appeared to expose students to the reality that not all decisions are participatory, and that resistance will not always achieve desired outcomes and, negotiations and mutual understanding of each other's interests and positions can lead to an amicable outcome. Moreover, participation in processes that do not achieve desired outcomes was demonstrated as being equally important to participation in those processes that do. This might not be the ideal empowerment scenario as outlined by Jennings et al. (2006) and the CYE framework, but it certainly provided the learners a real-world experience of decision-making.

\section{Engagement in critical reflection on interpersonal and sociopolitical processes}

In Questscope centres, critical reflection is prompted through the development of a ' $n u s$ almuwalad'; that is, a sentence formulated through group discussion of and debate about 
the chosen topic. In Irbid, a facilitator of a boys' centre spoke of how he had organised the nus al-muwalad around the topic of violence. Students were asked to create a film about violence and discrimination in school in which a student became ostracised from the group. The students created the storyline for the film by predicting the outcomes of each action. The plot went as follows:

The student seeks help from staff, only to be dismissed and asked to 'get on with it'. He tries to gain help from his teachers to improve his computer skills, but struggles. After sitting the final exam, the student is denied his certificate in a public ceremony and instead watches others collect theirs. He feels deflated, and decides to give up on learning computer skills.

The students filmed themselves acting out the plot on a camera provided by the centre. This was later edited by an external partner into a short movie. The film then served as a teaching resource for other classes where pedagogically, students watched the video, sitting in small groups and created mind maps of their thoughts about what happened and why. In doing so, the facilitator enabled the students to engage with critical issues of systemic discrimination in the education system. The discussion that stemmed from the creation of the film shaped the nus al-muwalad for that month and students critically analysed the topic in a series of subsequent classes.

The above learning activity is one example of Questscope's approach to youth empowerment through critical reflection and serves as an integral part of its Freirean model. As Freire (2000) argues, if people are not critically aware of the visible and invisible structures and processes that make up social institutions and practices, or of their own roles and actions within these domains, there is little room for empowerment. Jennings et al. (2006) also contend that youth are not truly empowered unless they are able to understand the underlying processes and practices of their environment.

Unfortunately, many of the Questscope centres were unable to engage in such a clear process of critical reflection. The same facilitator in Irbid suggests that this is largely due to difficulties in teaching the curriculum and finding time to perform activities for critical reflection:

We talk about this a lot in the classes, we discuss violence in the class, and we sit in groups and make mind-maps around violence. The problem is how do I teach maths, or Arabic at the same time, so much that they pass an exam? They already have so little time, and they are expected to pass the same tests as in the Jordanian schools? It is one or the other most of the time.

Such a pattern also emerged in Amman, where students were being taught Arabic with little interaction or critical reflection. A justification for adopting the conventional, rote learning approach was that the students were falling behind on an Arabic lesson:

Sometimes, we do critical reflection, but we were behind on an Arabic lesson so we had to do it today (Teacher, Amman)

In refugee contexts, certification is in high demand and seen as providing important benefits to individuals, families, communities and societies in, or recovering from, crisis (Kirk 2009). These findings raise important questions about the place and role of certification in the empowerment process. In the context of forced displacement, where young people in their host communities are excluded and vulnerable, and their educational expectations lead them to view rote learning as a route to recognised certification and then to the world of work, empowerment through critical reflection may not be perceived as an important pathway. Hence, educational provisions in refugee contexts would need to serve both the 
economic logic of education which is concerned with basic livelihood as well as broad edu-cational outcomes which enable learners to develop a critical understanding of the social, political and economic structures that surround them.

\section{Participation in sociopolitical processes to effect change}

In the case of Syrian refugee youth in these centres, there were no visible discussions about, or participation in, activities aimed at addressing the structures and processes that supress refugee opportunities, nor were there attempts to achieve some form of redistribution of resources or decision-making, favourable to refugee communities. Instead, the majority sought a means to be resilient, rather than hold roles to transform the unjust structures that marginalised refugees. Most participants expressed a desire to gain access to skilled trades, with mentions of mechanics and construction, without acknowledging the barriers limiting refugees' rights to employment in host countries. A Syrian student in Aljoun expressed his desire to work overseas rather than confront the limitations imposed on Syrian refugees in Jordan:

I have been in Jordan for three years now. I went to the Jordanian school for four months, but I left two years ago, it is not good there for Syrians. Now I have been here [at Questscope]

for two months. I need this certificate for work, to work, to go to the gulf [countries] and work, this place [gulf] is better for me, but I must have a certificate for this.

The Syrian refugees had high regards for education as an investment for the future. The hope for a safe return to Syria and to restart a normal life appeared to be a key motivation for continuing education. Many students in Marfaq and Irbid suggested that much of this influence came from their parents and a perception of future repatriation: 'my parents make me go here so I can get a better job when we go [back] home' (Student in Marfaq). A parent in Karak in attendance at a Questscope event expressed similar views:

I want my son to be able to get a better job when he finishes here and we go back to Syria. I didn't know if he could do it [study] here, but now I know.

Questscope recruiters also mentioned that parents regularly ask about certification before sending their children to join Questscope education programmes:

Two things they ask are when the school day is and when they have to be in school. We tell them it's two to three hours at maximum, and then they ask about the certificate - what's the system? When do we get it?, What is it?, What kind of certificate is it?, so I tell them it is a 10th grade certificate after two years. (Questscope recruitment officer in Irbid)

Students and parents appeared to see either repatriation or future employment in Jordan or abroad as viable options, and were merely trying to compensate for missed education so they could return to a 'normal routine', leaving little desire to participate in social change efforts.

\section{Integrated individual and community-level empowerment}

Questscope centres were found to have organised various events to bring students, family, Ministry of Education Liaison officers, facilitators and Questscope staff together. During Ramadan, this included an event in which all involved parties came together to share a meal. Through these events, education officials, youth and the broader community gained the opportunity to share experiences in the programme and promote its success. It was 
observed that the event was particularly effective at enabling meaningful interactions between youth groups, public officials and distinguished members of the community. A Ministry of Education official at an event reflected on a shift in his perception towards the education of Questscope students:

We thought, these kids can't be taught, what do we do! Now we see they can, they just need to be taught differently. (Jordanian Ministry of Education Liaison officer)

A facilitator in Karak agrees, noting:

What you need to know is we don't have any resources here, we don't have oil, we don't have minerals, or fields or anything. If we don't invest in our people - only through our people can we progress ... if we see a way to educate those people, we take notice. Now we see a way to do it.

Events such as these represented a form of integrated praxis, providing opportunities to advocate for Syrian causes such as the redistribution of resources, the continuation of existing support, tolerance for diversity and open governance structures. Zeldin, Camino and Calvert (2012) suggest that these forms of youth engagement can lead organisations to reflect on issues of representation, which can lead to improved outreach and more appropriate programming for diverse constituencies. Moreover, they can produce broader ripple effects in the community through wider visibility and by establishing new standards for other organisations (Zeldin 2004; Zeldin, Camino, and Calvert 2012). Pearrow (2008) also notes that communitybased intergenerational programmes have a significant social value not only in terms of youths' engagement with public officials to advocate for their programmes, but also in challenging stereotypes that portray youth as 'difficult', 'problematic' or a threat to the interests of stakeholders (Hilker and Fraser 2009).

Outside of these events, however, engagement with the wider community remained limited. Instead, small refugee communities were formed around the centres, created in part through the recruitment process. A Questscope education advocacy officer in Irbid describes the process of recruiting students to the centres:

We mainly recruit through personal connections to find students, then we go to the house and talk to them about the school, and then they will often connect us to someone else.

In Marfaq, this led to the majority of students being Syrian and knowing each other from the same town in Syria. They described themselves as 'one big family' (Syrian student in Marfaq), and felt that the Questscope education was just like being at home:

We love it here. This is just like being in school at home, with my friends. All our parents already know each other too.

In this particular circumstance, it became apparent that the students and centres were creating a microcosm of their Syrian community within the larger Jordanian community. A Questscope education coordinator explains that these micro-communities that formed around the centres 'support the refugee community and create opportunities to find informal employment'. They provided an opportunity for refugees to validate their capital in terms of employability skills, in a context in which it had otherwise been subject to a range of sanctions aimed at deterring competition for local jobs. Hunter and Staggenborg (1988,

253) call these 'networks of necessity' that are crucial mechanisms for the survival and sustenance of poor and vulnerable members of the refugee community. Yet in this scenario, empowerment appeared to be rather micro-level, and confined to an isolated community, 
risking removal of both incentive and access necessary to facilitate the achievement of social justice goals within Jordanian society.

\section{Conclusion}

The case of Questscope education programmes in Jordan provides an insightful example of an alternative educational practice for Syrian refugees, underpinning the idea of critical consciousness, mutual respect and dignity while providing highly valued certification, which may offer the hope for a stable livelihood in both the short and intermediate term. Crucially, the organisation has found a means of enrolling out-of-school youth into quality education, providing an important model for application in other refugee contexts.

However, this research has revealed that the transformative pedagogies underpinned by the Freirean notion of critical consciousness for Syrian refugee youth in Jordan are dis-torted by a series of intersecting factors, namely, the perception that it is antithetical to the goal of gaining certification, leading to a risk of manipulation of the programming into a microcosm of its uncritical, formal counterpart. Moreover, a sense of eventual repatriation or employment opportunities elsewhere can lead refugees to use school spaces for isolation from the larger Jordanian society and to the formation of Syrian micro-communities rather than coordinated, collective engagements with host communities. With critical conscious-ness at the foundation of an array of educational discourses, including peace education, citizenship education, values education, history education and critical education (Gill and Niens 2014), these findings raise concerns over the underpinning philosophies of a number of educational approaches in refugee contexts.

This research however, has not discounted the benefits of effective leadership skills, participatory decision-making, or the ability to critically reflect on interpersonal and sociopolitical processes. These attributes, along with educational certificates, may provide refugees with a more robust standing in the job market and a culture of participation and critical reflection that can lead to praxis. It has however, identified the need for practitioners and academics alike, to identify means of overcoming the perceived incompatibilities between the demands for certification and conscientisation in order to optimise Freirean pedagogies in refugee contexts. Our hope for education as a vehicle for peace, social justice, human rights and democracy may well depend on it.

\section{Acknowledgement}

Authors would like to thank Dr Curtis N. Rhodes, Jr., International Director of Questscope, Jordan and two anonymous reviewers for their valuable comments on the earlier draft of the paper.

\section{Disclosure statement}

No potential conflict of interest was reported by the authors.

\section{References}

AAP (American Academy of Paediatrics). 2012. "Early Childhood Adversity, Toxic Stress, and the Role of the Paediatrician." Paediatrics 129 (1): e224-e231. 
Ahmadzadeh, H., L. Hashem, J. Al Husseini, S. Wahby, M. Alasil, Z. Bali, and H. Waziri. 2014. Ensuring Quality Education for Young Refugees from Syria (12 - 25 Years) a Mapping Exercise Research Report. Oxford: Refugee Studies Centre.

Alvesson, M., and K. Sköldberg. 2009. Reflexive Methodology: New Vistas for Qualitative Research. 2nd ed. London: Sage Publications.

Andersson, I., H. Hinge, and C. Messina. 2011. Peace Education. CiCe Central Coordination Unit. London: Institute for Policy Studies in Education.

Betts, A., and P. Collier. 2015. Help Refugees Help Themselves, Foreign Affairs. https://www.foreignaffairs. com/articles/levant/2015-10-20/help-refugees-help-themselves.

Blair, C., D. Granger, and R. Peters Razza. 2005. "Cortisol Reactivity is Positively Related to Executive Function in Preschool Children Attending Head Start." Child Development 76 (3): 554-567.

Cargo, M., G. D. Grams, J. M. Ottoson, P. Ward, and L. W. Green. 2003. "Empowerment as Fostering Positive Youth Development and Citizenship." American Journal of Health Behavior 27: S66-S79. doi:10.5993/AJHB.27.1.s1.7.

Chinman, M. J., and J. A. Linney. 1998. "Toward a Model of Adolescent Empowerment: Theoretical and Empirical Evidence.” Journal of Primary Prevention 18 (4): 393-413. doi:10.1023/A:1022691808354.

Crisp, J., C. Talbot, and D. Cipollone. 2001. Learning for a Future: Refugee Education in Developing Countries. Geneva: United Nations Publications.

Davies, L. 2009. "Educating against Extremism: Towards a Critical Politicisation of Young People." International Review of Education 55 (2-3): 183-203. doi:10.1007/s11159-008-9126-8.

Dhingra, R. 2016. Losing Syria's Youngest Generation: The Education Crisis Facing Syrian Refugees in Jordan. http://reliefweb.int/report/jordan/losing-syria-s-youngest-generationeducation-crisis-facing-syrian-refugees-jordan.

Freire, P. 1985. The Politics of Education: Culture, Power and Liberation. Westport: Bergin and Garvey.

Freire, P. 2000. Pedagogy of the Oppressed. New York: Bloomsbury Publishing.

Freire, P. 2013. "Education and conscientização." In Education for Critical Consciousness, edited by P. Freire, 39-54. London: Bloomsbury Academic.

Gill, S., and U. Niens. 2014. "Education as Humanisation: Dialogic Pedagogy in Post-Conflict Peacebuilding." Compare: A Journal of Comparative and International Education 44 (February): 1-9. doi:10.1080/03057925.2013.864522.

Goodman, A., H. Joshi, B. Nasim, and C. Tyler. 2015. A Review for the Early Intervention Foundation Social and Emotional Skills in Childhood and Their Long-Term Effects on Adult Life. http://www. eif.org.uk/wp-content/uploads/2015/03/EIF-Strand-1-Report-FINAL1.pdf.

Hammond, J. L. 1998. Fighting to Learn: Popular Education and Guerrilla War in El Salvador. New Jersey, NJ: Rutgers University Press.

Hilker, L. M., and E. Fraser. 2009. Youth Exclusion, Violence, Conflict and Fragile States. http://www. gsdrc.org/docs/open/con66.pdf.

Hunter, A., and S. Staggenborg. 1988. 'Local Communities and Organised Action.' In Community Organizations: Studies in Resource Mobilization and Exchange, edited by C. Milofsky, 287. New York: Oxford University Press.

ILO. 2015. Access to Work for Syrian Refugees in Jordan: A Discussion Paper on Labour and Refugee Laws and Policies. https://data.unhcr.org/syrianrefugees/download.php?id=8919.

INEE. 2010. Minimum Standards For Education: Preparedness, Response, Recovery. http://www.ineesite. org/eietrainingmodule/cases/learningistheirfuture/pdf/Minimum_Standards_English_2010.pdf.

INEE. 2016. INEE Background Paper on Psychosocial Support and Social and Emotional Learning for Children and Youth in Emergency Settings. http://reliefweb.int/report/world/psychosocial-supportand-social-and-emotional-learning-children-and-youth-emergency.

Irigaray, T., J. B. Pacheco, R. Grassi-Oliveira, R. Fonseca, J. Leite, and C. H. Kristensen. 2013. "Child Maltreatment and Later Cognitive Functioning: A Systematic Review." Psicologia: Reflexão e Crítica 26 (2): 376-387.

JENA. 2015. Access to Education for Syrian Refugee Children and Youth in Jordan Host Communities. http://reliefweb.int/report/jordan/access-education-syrian-refugee-children-andyouth-jordan-host-communities-joint. 
Jennings, L. B., D. M. Parra-Medina, D. K. Hilfinger-Messias, and K. McLoughlin. 2006. "Toward a Critical Social Theory of Youth Empowerment." Journal of Community Practice: 14: 31-55. doi:10.1300/J125v14n01_03.

Kabeer, N. 1999. "Resources, Agency, Achievements: Reflections on the Measurement of Women's Empowerment." Development and Change 30 (3): 435-464. doi:10.1111/1467-7660.00125.

Kia-Keating, M., and B. H. Ellis. 2007. "Belonging and Connection to School in Resettlement: Young Refugees, School Belonging, and Psychosocial Adjustment." Clinical Child Psychology and Psychiatry 12 (1): 29-43. doi:10.1177/1359104507071052.

Kim, S., C. Crutchfield, C. Williams, and N. Hepler. 1998. "Toward a New Paradigm in Substance Abuse and Other Problem Behavior Prevention for Youth: Youth Development and Empowerment Approach.” Journal of Drug Education 28 (1): 1-17. doi:10.2190/5ET9-X1C2-Q17B-2G6D.

Kirk, J. 2009. Certification Counts: Recognizing the Learning Attainments of Displaced and Refugee Children. Paris: IIEP.

McCaffery, J. 2007. "Transformative Literacy, Conflict Resolution and Peace-building: Examples from Sierra Leone and Sudan." In Education, Conflict and Reconciliation: International Perspectives, edited by F. Leach and M. Dunne, 131-150. Bern: Peter Lang.

Mercy Corps. 2014. Advancing Adolescence: Getting Syrian Refugee and Host-Community Adolescents Back on Track. http://www.mercycorps.org/sites/default/files/MercyCorps_ SyrianAdolesenceAssessment_0614.pdf.

Mohajer, N., and J. Earnest. 2009. "Youth Empowerment for the Most Vulnerable: A Model Based on the Pedagogy of Freire and Experiences in the Field." Health Education 109: 424-438. doi:10.1108/09654280910984834.

Nyirenda, J. 1996. "The Relevance of Paulo Freire's Contributions to Education and Development in Present Day Africa." Africa Media Review 10: 1-20. doi:0258-4913.

Oxford Stakeholders Study. 2011. Strengthening Youth Opportunities: A Pilot Impact and Process Study of Empowerment-Based Non-Formal Education for out-of-School Youth in Amman. Jordan. http:// questscope.org/sites/default/files/documents/Attachment\%205\%20-\%20B\%20Oxford_s\%20 Impact\%20Study-Stakeholder\%20Report-2011.pdf.

Questscope. 2016. Internal Questscope Records.

Pearrow, M. M. 2008. "A Critical Examination of an Urban-Based Youth Empowerment Strategy: The Teen Empowerment Program." Journal of Community Practice 16 (4): 509-525. doi:10.1080/10705420802514213.

Price, P. 2011. "Education in Emergencies: Benefits, Best Practices, and Partnerships." The Applied Anthropologist 31 (2): 54-57.

Rodgers, G. 2004. "Hanging out with Forced Migrants: Methodological and Ethical Challenges." Forced Migration Review 21: 48-49.

SCPR. 2015. Confronting Fragmentation: Impact of Syrian Crisis Report. http://www.sy.undp.org/ content/syria/en/home/library/poverty/confronting-fragmentation.html.

Taylor, P. V. 1993. The Texts of Paulo Freire. Buckingham: Open University Press.

UNHCR. 2011. The Benefits of Belonging: Local Integration Options and Opportunities for Host Countries, Communities and Refugees. http://www.unhcr.org/uk/publications/legal/4e3276e26/ benefits-belonging-local-integration-options-opportunities-host-countries.html.

UNHCR. 2016a. Humanitarian Education Accelerator. Accessed March 13, 2016.

wwwww UNHCR. 2016b. Jordan: UNHCR Operational Update May 2016.

UNHCR. 2016c. Syria Regional Refugee Response - Regional Overview. Accessed June 10, 2016. http:// data.unhcr.org/syrianrefugees/regional.php

UNHCR. 2016d. UNHCR - Figures at a Glance. http://www.unhcr.org/figures-at-a-glance.html. Urdal,

H. 2006. "A Clash of Generations? Youth Bulges and Political Violence." International Studies Quarterly 50 (July): 607-629. doi:10.1111/j.1468-2478.2006.00416.x.

Zeldin, S. 2004. "Youth as Agents of Adult and Community Development: Mapping the Processes and Outcomes of Youth Engaged in Organizational Governance." Applied Developmental Science 8 (2): 75-90. Lawrence Erlbaum Associates, Inc. doi:10.1207/s1532480xads0802_2. 
Zeldin, S., L. Camino, and M. Calvert. 2012. "Toward an Understanding of Youth in Community Governance: Policy Priorities and Research Directions.” Análise Psicológica 25 (1): 77-95. doi:10.14417/ap.431.

Zimmerman, M. 1995. "Psychological Empowerment : Issues and Illustrations." American Journal of Community Psychology 23 (5): 581-599. 